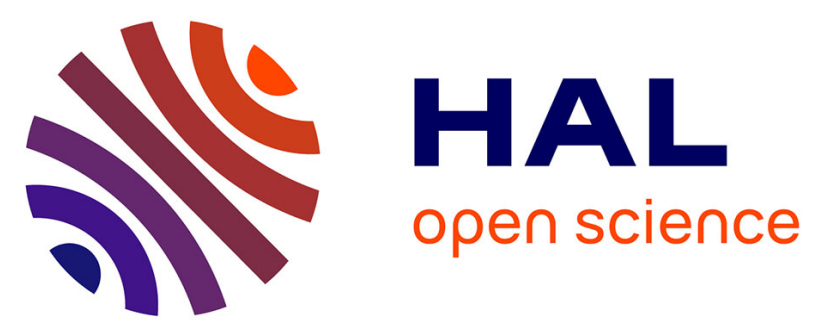

\title{
Identification of the metallurgical parameters explaining the corrosion susceptibility in a 2050 aluminium alloy
}

\author{
Mathilde Guérin, Joël Alexis, Eric Andrieu, Lydia Laffont-Dantras, Williams
} Lefebvre, Grégory Odemer, Christine Blanc

\section{- To cite this version:}

Mathilde Guérin, Joël Alexis, Eric Andrieu, Lydia Laffont-Dantras, Williams Lefebvre, et al.. Identification of the metallurgical parameters explaining the corrosion susceptibility in a 2050 aluminium alloy. Corrosion Science, 2016, 102, pp.291-300. 10.1016/j.corsci.2015.10.020 . hal-01264384

\section{HAL Id: hal-01264384 \\ https://hal.science/hal-01264384}

Submitted on 4 Mar 2016

HAL is a multi-disciplinary open access archive for the deposit and dissemination of scientific research documents, whether they are published or not. The documents may come from teaching and research institutions in France or abroad, or from public or private research centers.
L'archive ouverte pluridisciplinaire HAL, est destinée au dépôt et à la diffusion de documents scientifiques de niveau recherche, publiés ou non, émanant des établissements d'enseignement et de recherche français ou étrangers, des laboratoires publics ou privés. 


\section{Open Archive TOULOUSE Archive Ouverte (OATAO)}

OATAO is an open access repository that collects the work of Toulouse researchers and makes it freely available over the web where possible.

This is an author-deposited version published in : http://oatao.univ-toulouse.fr/ Eprints ID : 14698

To link to this article : DOI : 10.1016/j.corsci.2015.10.020

URL : http://dx.doi.org/10.1016/j.corsci.2015.10.020

To cite this version : Guérin, Mathilde and Alexis, Joël and Andrieu, Eric and Laffont-Dantras, Lydia and Lefebvre, Williams and Odemer, Grégory and Blanc, Christine Identification of the metallurgical parameters explaining the corrosion susceptibility in a 2050 aluminium alloy. Corrosion Science, Vol.102. pp.291-300. ISSN 0010-938X

Any correspondance concerning this service should be sent to the repository administrator: staff-oatao@listes-diff.inp-toulouse.fr 


\title{
Identification of the metallurgical parameters explaining the corrosion susceptibility in a 2050 aluminium alloy
}

\author{
Mathilde Guérin ${ }^{\mathrm{a}, \mathrm{b}}$, Joël Alexis ${ }^{\mathrm{b}}$, Eric Andrieu ${ }^{\mathrm{a}}$, Lydia Laffont ${ }^{\mathrm{a}}$, Williams Lefebvre ${ }^{\mathrm{c}}$, \\ Grégory Odemer ${ }^{\mathrm{a}}$, Christine Blanc ${ }^{\mathrm{a}, *}$ \\ a Université de Toulouse, Institut CARNOT CIRIMAT, UPS/CNRS/INPT, ENSIACET, 4 allée Emile Monso, 31030 Toulouse, France \\ ${ }^{\mathrm{b}}$ Université de Toulouse, LGP, ENIT/INPT, 47 Avenue d'Azereix, 65016, Tarbes, France \\ ' Université de Rouen, GPM-UFR Sciences et Techniques, Avenue de l'Université-BP12, 76801, Saint Etienne du Rouvray, France
}

Keywords:
Alloy
Aluminium
STEM
Intergranular corrosion
Interfaces

\section{A B S T R A C T}

The corrosion behaviour of a 2050 aluminium alloy was studied in a NaCl solution. The structure of precipitation did not fully explain the susceptibility to intergranular (in the -T34 state) and intragranular corrosion for the aged state (the -T8 state). A relationship between the nature of interfaces, the grains characteristics (size, internal misorientation and orientation according to the plane exposed to the electrolyte) on one hand and the corrosion susceptibility of the alloy on the other hand was clearly established. Galvanic coupling between grains with different internal misorientations helped to explain the intergranular corrosion susceptibility of the -T34 state.

\section{Introduction}

New generation of Al-Cu-Li-X alloys shows remarkable combination of density, mechanical properties and corrosion resistance. Although other phases can be observed in these alloys, the precipitation of $\mathrm{T}_{1}-\mathrm{Al}_{2} \mathrm{CuLi}$ phase is commonly considered as a major parameter to explain the corrosion behaviour of these alloys [1-9]. This intermetallic phase possesses a more negative corrosion potential than the matrix [2,6]. When the material is exposed to an aggressive medium, a galvanic coupling between the $T_{1}$ phase and the matrix occurs in favour of the matrix. In the -T34 metallurgical state, because of the presence of $\mathrm{T}_{1}$ particles only at the grain boundaries, galvanic coupling leads to the dissolution of the grain boundaries with a more negative corrosion potential than for the grains. To desensitise the alloy to intergranular corrosion, an aging treatment is applied to the material. This leads to the precipitation of $\mathrm{T}_{1}$ particles both in the grains and at the grain boundaries, leaving the aged state (-T8). For a -T8 sample, because of this structure of precipitation, the corrosion potentials of the matrix and the

\footnotetext{
* Corresponding author at: Université de Toulouse, CIRIMAT, UPS/CNRS/INPT, 4 allée Emile Monso, BP 44362, 31030 Toulouse Cedex 4, France.

Fax: +330534323498.

E-mail address: christine.blanc@ensiacet.fr (C. Blanc).
}

grain boundaries are quite similar. Consequently, galvanic coupling does not occur between the grain and the grain boundaries and the material is susceptible to intragranular corrosion [2-4].

Our results from previous work confirmed the susceptibility of an AA 2050 alloy to intragranular corrosion after an ageing treatment at $155^{\circ} \mathrm{C}$ for $30 \mathrm{~h}$ and correlated this to the homogeneous distribution of $\mathrm{T}_{1}$ phase particles in the grains and at the grain boundaries [9]. For the AA 2050-T34 alloy, susceptible to intergranular corrosion, a major part of corroded grain boundaries did not evidence the presence of $\mathrm{T}_{1}$ precipitates. This result suggested that the presence of the $T_{1}$ phase was not necessary to induce a susceptibility to intergranular corrosion in an AA 2050-T34 alloy. Furthermore, for both -T8 and -T34 alloys, preferential dissolution of some grains and grain boundaries was respectively observed while, for -T8 alloy for example, homogeneous distribution of $\mathrm{T}_{1}$ precipitates was observed both in the grains and at the grain boundaries. These results suggested that parameters different than the structure of precipitation should contribute to explain the corrosion behaviour of the AA 2050 alloy. This should be in agreement with results found in literature. For example, Luo et al. showed that a relationship exists between the dislocation density in a grain and the ability of the grain boundary to be corroded [10]. Kim et al. showed that the grain boundary character distribution (GBCD) has a great effect on intergranular corrosion susceptibility of aluminum in $\mathrm{HCl}$ [11]. Ralston et al. worked on the influence of the grain size on 


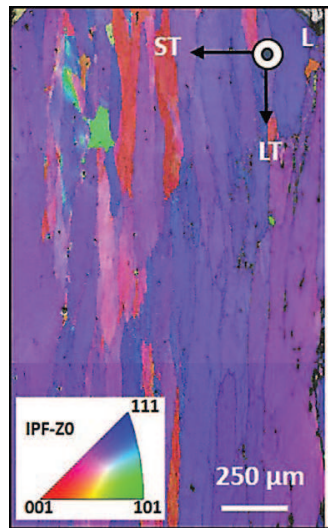

Map 1: Identification of Map 2: Identification of the grain orientation nature of the interfaces

Scanning by EBSD IPFZO of the surface exposed (1.5 $\times 3$ $\mathrm{mm}^{2}$ ) to the electrolyte before corrosion tests

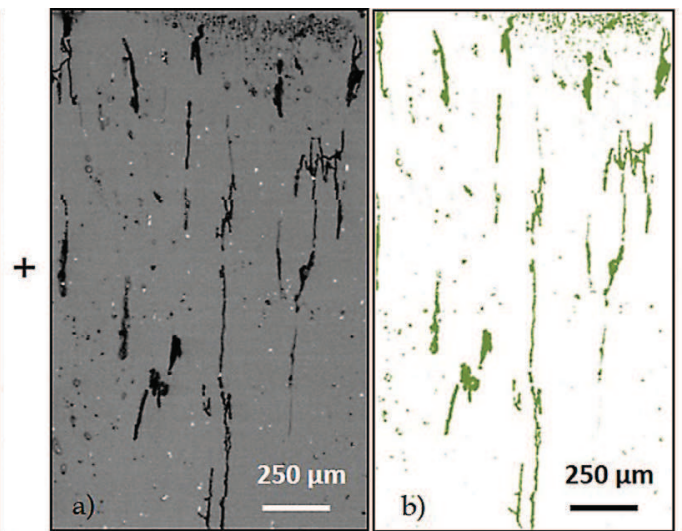

Maps 3: Localization of corrosion defects

a) Scanning by SEM of the corroded surface after immersion test in $0.7 \mathrm{M} \mathrm{NaCl}$ during 72 hours b) Image analysis

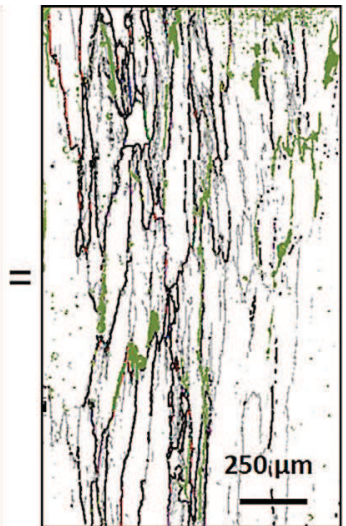

Map 4: Corroded surface

Map $3 b$ superimposed to $\operatorname{map} 2$

Fig. 1. Methodology used for studying the impact of different metallurgical parameters at the polycrystal scale on the corrosion behaviour of AA 2050.

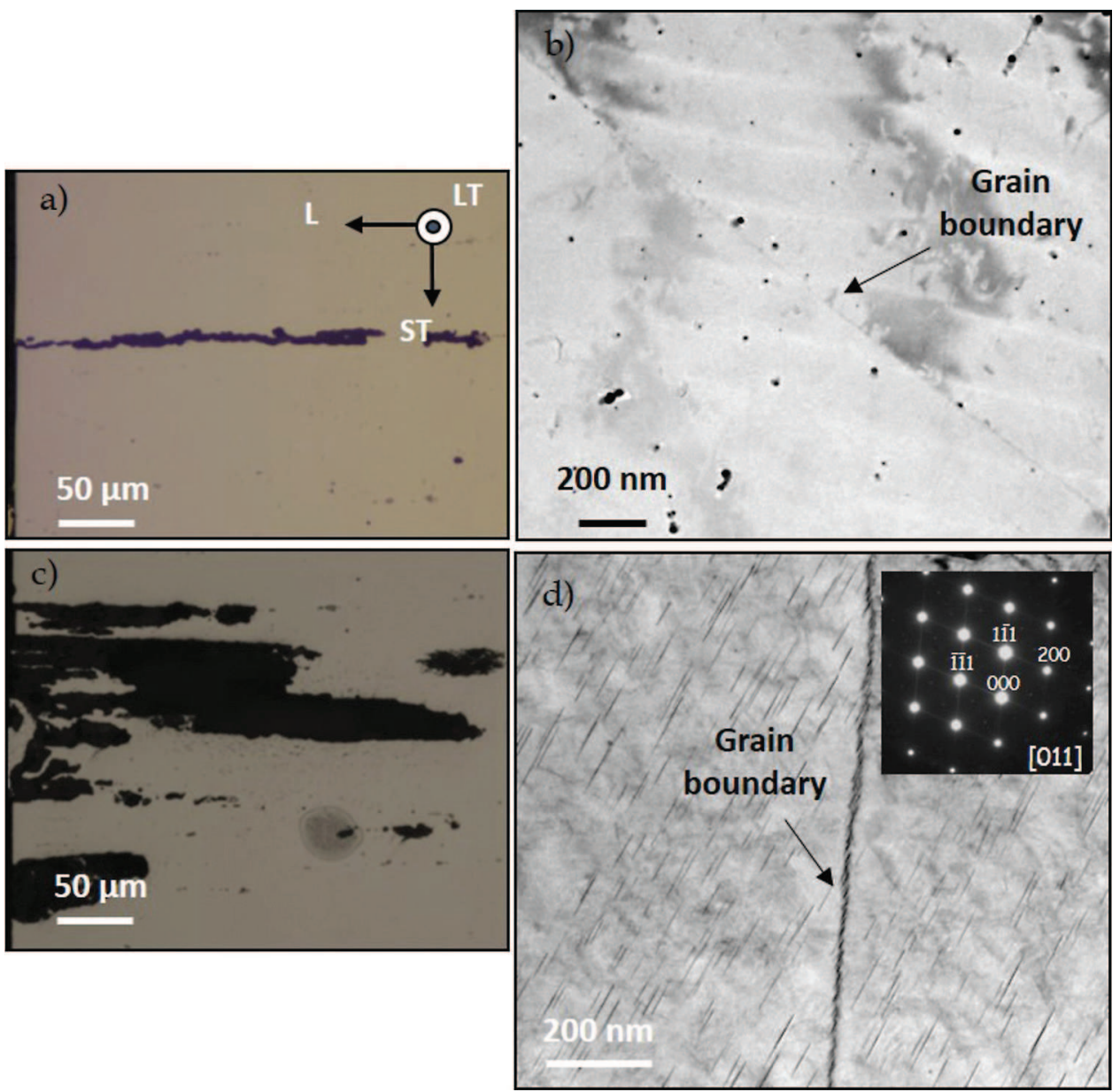

Fig. 2. Optical microscope observations of (a) intergranular corrosion in the -T34 sample and (c) intragranular corrosion in the -T8 sample. Bright-field TEM images of (b) the -T34 sample and (d) the -T8 sample.

the corrosion susceptibility of a material and noticed that the 'grain size-corrosion resistance' relationship is complex. They suggested that this complexity could be increased due to the heterogeneity of the grain size in a sample [12].

The aim of this study was to determine the origin of the susceptibility to intergranular and intragranular corrosion for AA 2050-T34 and AA 2050-T8 alloys respectively. The structure of precipitation was considered. However, attention was also paid to microstructural parameters at the polycrystal scale: this means that the nature of the interfaces (either grain boundaries or subgrain boundaries corresponding to the level of misorientation at the interfaces), the internal misorientation and size of the grains, and their orientation 


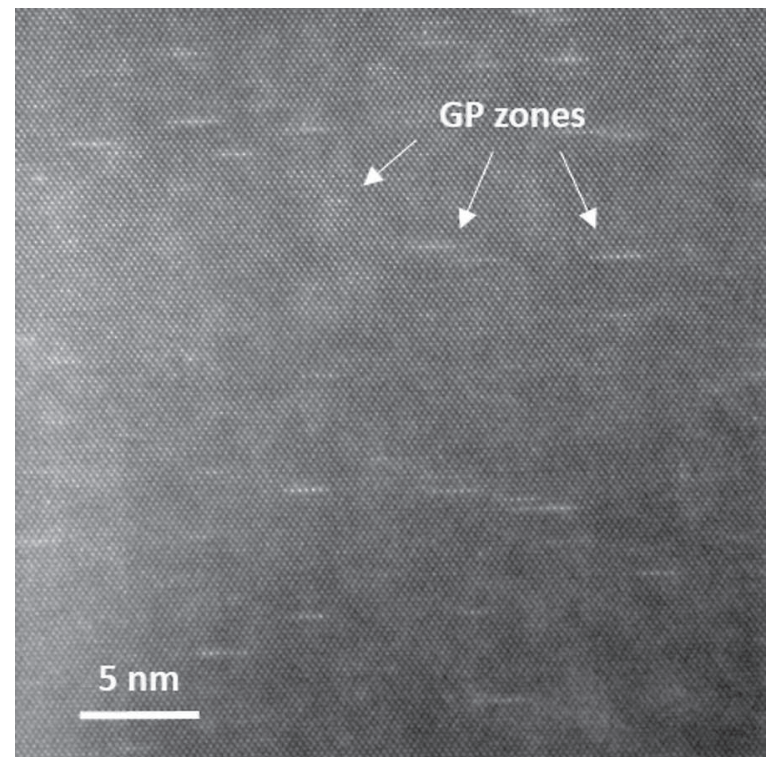

Fig. 3. HAADF STEM observation of GP zones along a $<110>$ axis of the Al matrix in the AA 2050-T34 alloy.

with respect to the plane exposed to the electrolyte were considered as potential critical metallurgical parameters influencing the corrosion susceptibility of the AA 2050 alloy. To study the impact of these microstructural parameters, electron backscatter diffraction (EBSD) analyses were performed on healthy and corroded samples.

\section{Experimental procedure}

\subsection{Material}

The material used for this study was an aluminium-copper-lithium AA 2050-T34 alloy (Al base, 3.86\% Cu, $0.86 \% \mathrm{Li}$, wt.\%) provided by Constellium (France). The material was received as a $50 \mathrm{~mm}$ thick plate formed by hot rolling and followed by solution heat treatment, water quenching and stretching to achieve the final -T34 metallurgical state. A piece of the plate was aged and corresponds to a -T8 metallurgical state. Due to the rolling process, the microstructure of both the -T34 and -T8 samples exhibited a high degree of anisotropy. Observations using optical microscopy (OM) of the thick plate showed that the grains were highly elongated in the rolling direction. The average sizes in the transverse (LT) and short transverse (ST) directions were 350 and $60 \mu \mathrm{m}$, respectively, with a large discrepancy in size from one grain to another. In the longitudinal (L) direction, the discrepancy is such that the calculation of a mean value is meaningless. Further EBSD analysis revealed two populations of grains: one population of large polygonised grains (with sizes varying from $350 \mu \mathrm{m}$ to $5 \mathrm{~mm}$ in the L direction) and another population of recrystallised grains with smaller dimensions (between $5 \mu \mathrm{m}$ and $20 \mu \mathrm{m}$ in the L direction).

\subsection{Study of the structure of precipitation of the AA 2050 alloy}

In order to take into account the structure of precipitation in the corrosion susceptibility of the AA 2050 alloy, a transmission electron microscope (TEM) in the scanning transmission electron microscopy (STEM) mode, which has a high degree of local precision, was used. STEM observations were recorded using a JEOL ARM 200F equipped with a Schottky FEG (field emission gun) and a probe $\mathrm{C}_{\mathrm{s}}$-corrector operating at $200 \mathrm{kV}$. The HAADF-STEM (High Angle Annular Dark Field) and LAADF-STEM (Low Angle Annular Dark Field) images were recorded with a $0.1 \mathrm{~nm}$ FWHM electron probe size of $30 \mathrm{mrad}$ semi-convergence angle. The detector ranges were set to 54-220 mrad for HAADF and 24-54 mrad for LAADF. The HAADF and LAADF signals are dominated by Z-contrast and diffraction contrast, respectively. For these techniques, the samples were prepared using mechanical polishing to obtain a $100 \mu \mathrm{m}$-thick slice followed by electrolytic polishing to make a portion of the sample transparent to electrons.

\subsection{Study of the critical microstructural parameters at the polycrystal scale}

EBSD analyses were performed for the -T34 and -T8 samples using a JEOL 7000F field emission scanning electron microscope equipped with a Nordlys II $\mathrm{F}+$ camera at an accelerating voltage of $15 \mathrm{kV}$. The EBSD analyses were helpful in both analysing the microstructure of the alloy and characterising the corrosion damage after the tests. All of the corrosion tests were performed over $72 \mathrm{~h}$ and were conducted in a continuous immersion at open circuit potential in a $0.7 \mathrm{M}$ solution of $\mathrm{NaCl}$, which was prepared by dissolving Normapur chemical salts in distilled water. During the tests, the solution was stirred and opened to the air. The temperature was maintained at $25^{\circ} \mathrm{C}$ using a Julabo refrigerated circulator. For each sample, EBSD maps were performed on the same $1.5 \mathrm{~mm} \times 3 \mathrm{~mm}$ area with a step size of 1-2 $\mu \mathrm{m}$ in the (LT-ST) plane both before and after the corrosion tests. During the corrosion tests, only this zone was exposed to the electrolyte (a varnish was painted on to protect the rest of the surface). The surface exposed to the electrolyte was large enough to obtain representative results. Overall, for each sample, more than 250 grains were analysed. The EBSD data were then post-processed using the commercial orientation imaging software package Oxford Channel 5. To minimise measurement errors, all grains comprising less than 3 pixels were automatically removed from the maps prior to data analysis. In addition, to eliminate spurious boundaries caused by orientation noise, a lower limit boundary misorientation cut-off of $2^{\circ}$ was used. The analyses permitted the determination of the orientation of the grains (see Fig. 1, map 1) and the nature of the interfaces (see Fig. 1, map 2). In this work, the word 'interfaces' refers to the grain boundaries independent of their level of misorientation. A $10^{\circ}$ criterion was used to differentiate low angle grain boundaries (i.e. subgrain boundaries) and high angle grain boundaries (i.e. grain boundaries). This misorientation was chosen based on data available for pure aluminium [13]. Two 

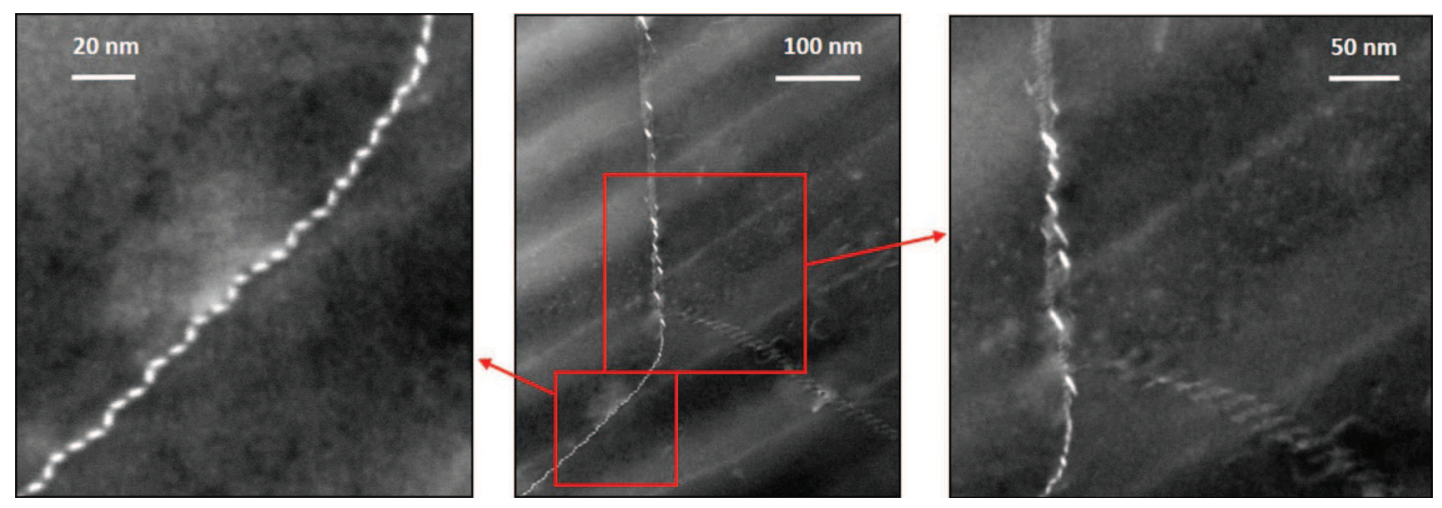

Fig. 4. HAADF STEM images of subgrain boundaries in the AA 2050-T34 alloy (Z-contrast).
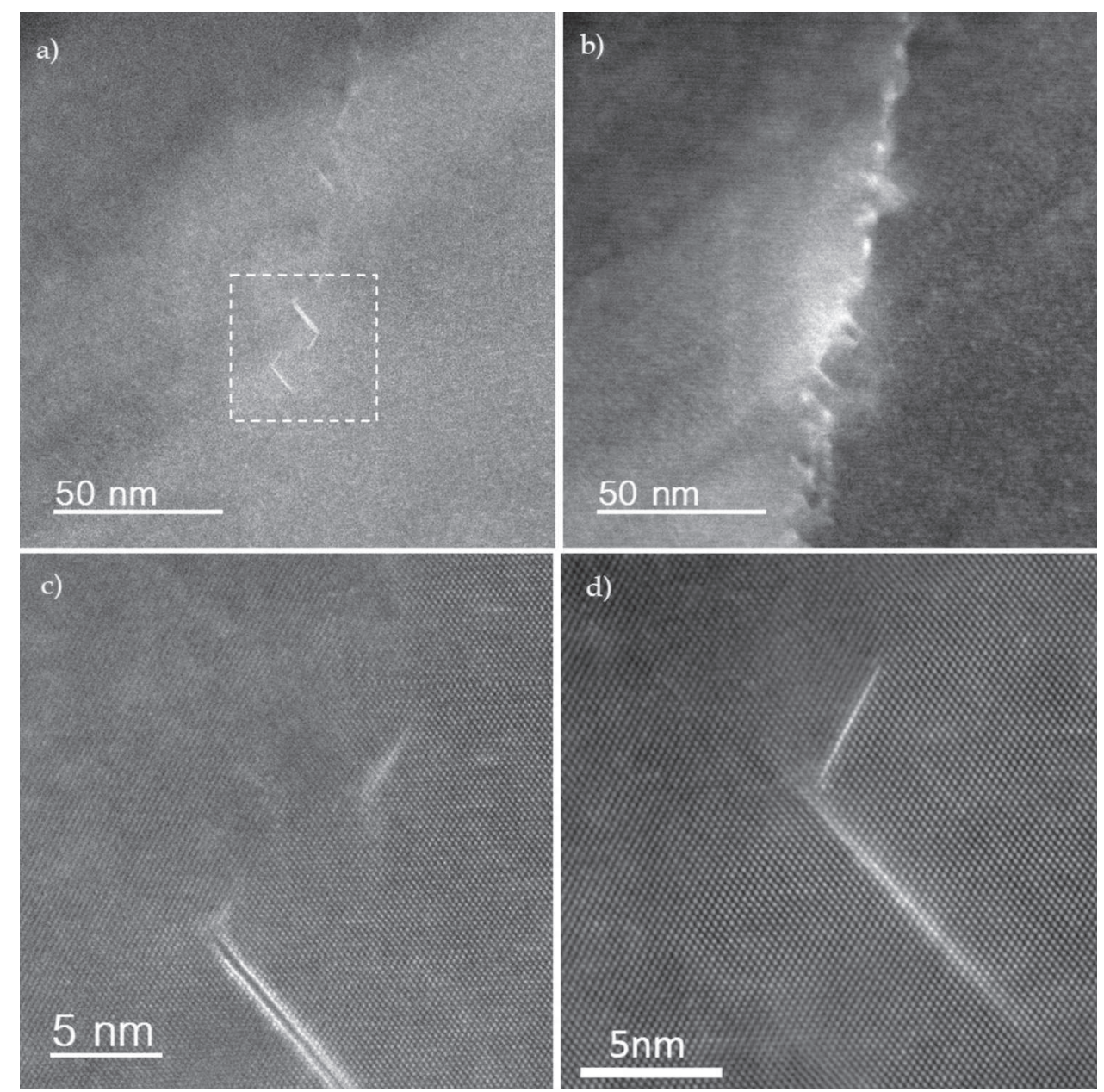

Fig. 5. (a) HAADF STEM (i.e. Z-contrast) and (b) LAADF STEM (i.e. diffraction contrast) images of the same region in the AA 2050 -T34 alloy. The region to the right is in perfect $<110>$ orientation whereas the crystal orientation slightly changes across the subgrain boundary identified by the alignment of dislocations in (a). This slight change of crystal orientation is clearly visible on the higher magnification HAADF STEM images displayed in (c) and (d), which show precipitates indicated by a white dotted square in (a).

categories of grain boundaries were distinguished: coincidence site lattice grain boundaries (CSL) and random grain boundaries. In coincident site lattice grain boundaries, the degree of fit $(\Sigma)$ between the structures of the two grains is described by the reciprocal of the ratio of coincidence sites to the total number of sites oriented in opposition to the random grain boundaries where the structure was observed as being disorganised. The grain size was quantified by measuring the grain area and calculating the equivalent grain diameter assuming each grain as a circle. After the corrosion tests, all the corroded interfaces and grains in the same zone were analysed. This represented approximately 50 interfaces (for the -T34 metallurgical state) and 15 grains (for the -T8 metallurgical state) in each sample. The analysis was reproduced twice for each metallurgical state leading to similar conclusions. After the testing, the corrosion products were removed using gentle mechanical polishing. The corroded zone was analysed using SEM with the electron backscatter detector to easily identify any corrosion defects (see Fig. 1, map 3a). The corrosion defects were isolated using image analysis (Image J software, see Fig. 1, map 3b). This last map was superimposed on map 1 or map 2 to obtain a corrosion 
map (see Fig. 1, map 4). The misorientation level for each corroded interface and the characteristics of the adjacent grains (for the -T34 metallurgical state) or of the corroded grains (for the -T8 metallurgical state) were extracted from map 4. The grain characteristics studied over this area included the size, the internal misorientation and the orientation relative to the plane exposed to the electrolyte.

\section{Experimental results and discussion}

As already discussed, a previous study on the same material revealed a susceptibility to intergranular corrosion for material in the -T34 state (Fig. 2a) and to intragranular corrosion in the -T8 state (Fig. 2c) [9]. TEM observations for -T8 samples agreed with the literature; the $\mathrm{T}_{1}$ phase precipitates were observed both in the grains and at the grain boundaries, explaining the susceptibility to intragranular corrosion (Fig. 2d). For the -T34 samples, no $\mathrm{T}_{1}$ precipitate was observed in the major parts of the grain boundaries (Fig. 2b).

\subsection{Corrosion behaviour of the AA 2050-T34 alloy}

The corrosion behaviour of the system investigated being strongly dependent on the structure of precipitation as suggested by the literature [1-9], it is necessary to determine whether $T_{1}$ and/or $\theta^{\prime}$ precipitates, that are also expected in such an alloy, can be observed in the T34 state. Because previous TEM observations did not allow the presence of $T_{1}$ precipitates to be evidenced in the major part of the grain boundaries, HAADF STEM observations were performed. They revealed first that only Cu-rich GP zones are identified in the matrix (Fig. 3) away from subgrain or grain boundaries, as expected. The length of these GP zones measured by projection along a $<110>$ axis is ranging between 1 and $3 \mathrm{~nm}$.

Special attention was paid to the characterization of subgrain boundaries and HAADF STEM images (Fig. 4) indicated that precipitates were already present along these interfaces. However, the density of precipitation was found to strongly vary from one subgrain boundary to another or along the same interface. In order to reveal elastic distorsions induced by the dislocations associated to these interfaces, LAADF STEM mode was used. Such a method has revealed its relevance for the imaging of dislocations in STEM [14]. In the AA 2050-T34 alloy, the same regions were simultaneously imaged in LAADF (Fig. 5b) and HAADF STEM (Fig. 5a) to unambiguously dissociate the contrast associated with a subgrain boundary (i.e. the alignment of dislocations across which the crystal orientation is slightly titled) to the $\mathrm{Z}$-contrast revealing the eventual presence of precipitates. Fig. 5 shows a subgrain boundary in a nearly $\langle 110\rangle$ orientation. Precipitates were clearly visible in some regions of this interface and were displayed in larger magnification in Fig. $5 c$ and d. Across these two images, from right to left, the loss of lattice resolution in the Al-matrix was due to a small disorientation of the lattice across the subgrain boundary. In Fig. 5c, the precipitate in the lower part of the image exhibited a typical contrast of a $\mathrm{T}_{1}$ precipitate along $\langle 110\rangle$ zone axis of aluminium, as reported in the literature $[15,16]$. The $\mathrm{Cu}$-rich planar defects lying along $\{111\}$ planes of aluminium in Fig. $5 d$ could not be clearly identified. The recent work by Gao et al. [17] has reported GP-T 1 zones, which structure did not correspond to the Cu-rich planar defects in Fig. 5. The GP-T 1 zones reported by Gao et al. actually display two Cu-rich planes parallel to $\{111\} \mathrm{Al}$, separated by a region with a composition that could not be determined unambiguously though its contrast seems to indicate that it consists of a single plane of aluminium. Our observations were more consistent with those made by Araullo-Peters et al. by atom probe tomography [18]. These authors have demonstrated a complex coupling between $\mathrm{Mg}$ and $\mathrm{Cu}$ segregations along dislocations with the formation of planar defects enriched in $\mathrm{Cu}$, identified as $\mathrm{T}_{1}$ precursors. Nevertheless, the mechanism of formation of $\mathrm{T}_{1}$ precipitates falls outside the scope of this paper, which purpose is to relate microstructural characterization to the corrosion behaviour of the AA2050-T34 alloy.

The main result here was that, in the T34 state, the alloy already contained $\mathrm{T}_{1}$ precipitates and other planar defects enriched in copper along subgrain boundaries. Lithium could also be present in the interfaces but, due to its low amount, it was impossible to detect this element. Despite the fact that no $\theta^{\prime}$ precipitate could be observed, we cannot exclude that some of these precipitates were present in the AA2050-T34 alloy along interfaces. The density of precipitates and planar defects strongly varied from one subgrain to another and we made the assumption that these variations were due to the nature of dislocations present in the subgrain boundaries. As suggested by several authors, a grain boundary with a high degree of atomic disarrangement should react more with impurities or alloying elements than a grain boundary with high coincidence level or even than a grain boundary of low angle misorientation [19-21]. This suggested that the level of misorientation of interfaces could be correlated to their corrosion susceptibility. A detailed investigation was hence required to estimate the possibility of such a correlation. This investigation, which was performed using EBSD analyses, is presented hereafter.

The results of the EBSD analyses performed prior to corrosion tests for the AA 2050-T34 sample are presented in Fig. 6. The distribution of interfaces according to their level of misorientation is shown in Fig. 6a. The level of misorientation of each interface was determined by measuring the misorientation between the grains situated on both sides of the interface. The results showed that $85 \%$ of interfaces were subgrain boundaries and only $15 \%$ were grain boundaries. Among the grain boundaries, 20\% were CSL grain boundaries and $80 \%$ were random grain boundaries. $\Sigma 3$ interfaces represented the majority of the $\operatorname{CSL}(35 \%$, Fig. 6b). Therefore, during analysis of the corroded samples, only the $\Sigma 3$ CSL grain boundaries were considered.

After completing the corrosion tests in the AA 2050-T34 sample, the corroded interfaces were located, and the levels of misorientation were recorded (Fig. 1). The analysis was performed on 50 corrosion defects, and led to the establishment of a relationship between the level of misorientation of an interface and its susceptibility to corrosion. Fig. 6a shows the corroded interface frequency according to their misorientation level. The distribution was different from the data taken prior to the corrosion test. A total of $70 \%$ of the corroded interfaces were grain boundaries whereas only $30 \%$ of the corroded interfaces were subgrain boundaries. Considering the high proportion of subgrain boundaries, these results suggest a higher resistance to corrosion of the subgrain boundaries. Moreover, among the corroded grain boundaries, the results showed that the most misoriented interfaces tended to be more susceptible to corrosion. The strong reactivity of the grain boundaries with a high level of misorientation may be linked to their disarranged structure and correlated with their high energy [19]. On the contrary, the resistance to corrosion of the subgrain boundaries should be associated with their low energy. These results were consistent with other work on various metals [20,22-24]. It should be noted that the interface susceptibility to corrosion, and in particular of some subgrain boundaries compared to the others, may also be explained by their chemical composition and structure of precipitation, as highlighted in the STEM-HAADF observations. It will be interesting to study the relationship between the chemical composition/structure of precipitation of an interface and its level of misorientation but this should be the subject of future study. Concerning the susceptibility to corrosion of the CSL grain boundaries, only four corrosion defects at $\Sigma 3$ grain boundaries were identified. An intergranular corrosion susceptibility index was determined by the ratio of the proportion of corrosion defects corresponding to 

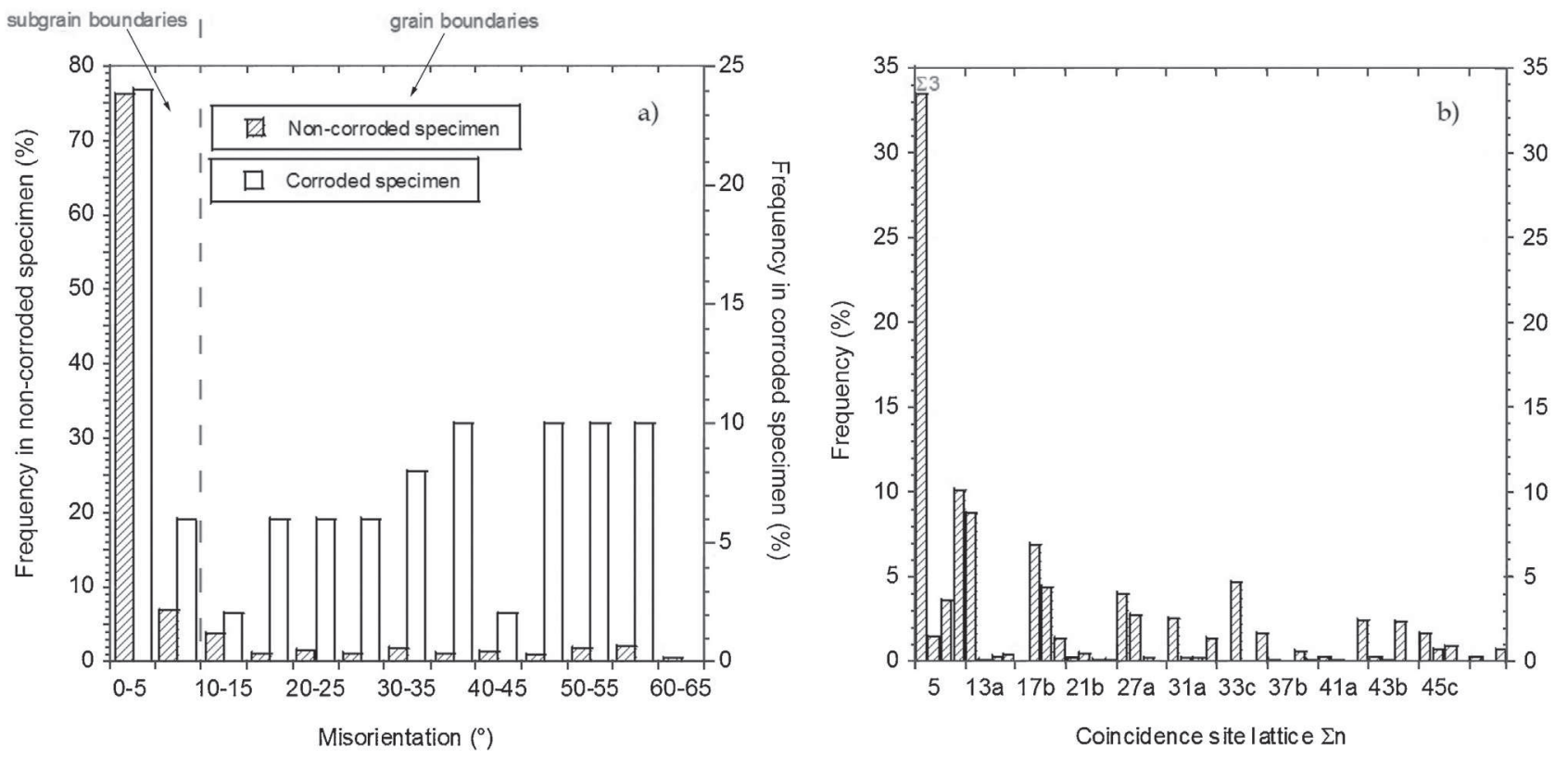

Fig. 6. AA 2050-T34 alloy-(a) Distribution of the level of misorientation of the interfaces before and after the corrosion tests; (b) distribution of the CSL grain boundaries before corrosion tests.
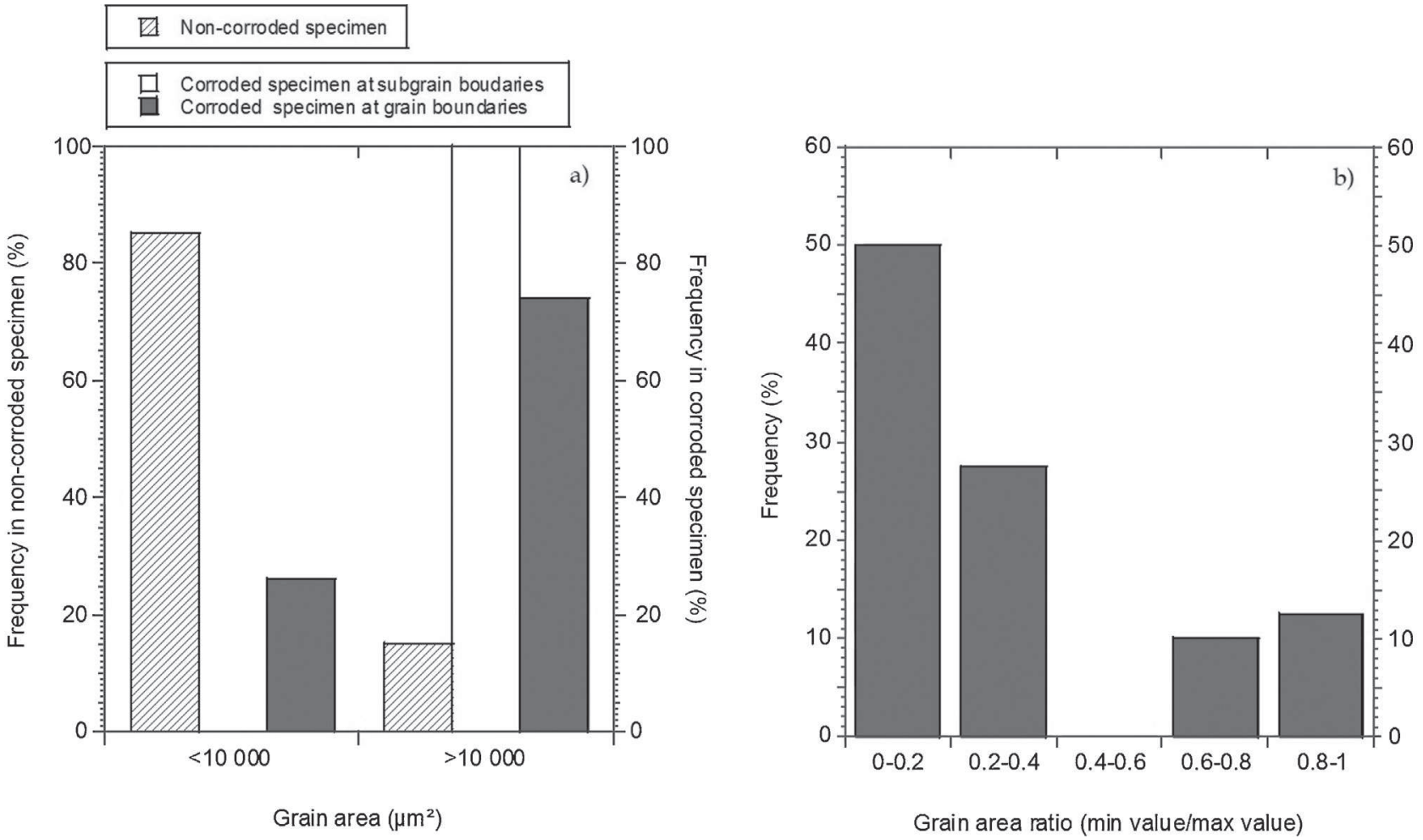

Fig. 7. AA 2050-T34 alloy-(a) Distribution of the grain surface areas before and after the corrosion tests for corrosion at subgrain boundaries and at grain boundaries; (b) distribution of the grain surface area ratio of the grains situated on both sides of the corrosion defects at the grain boundaries.

Table 1

Statistical analysis of the intergranular corrosion in the AA 2050-T34 alloy based on the nature of the interfaces at the polycrystal scale.

\begin{tabular}{lll}
\hline Nature of the interfaces & Subgrain boundaries & Random grain boundaries \\
\hline \% In non-corroded specimen (a) & 85 & 12 \\
\% In corroded specimen (b) & 30 & 62 \\
Intergranular corrosion susceptibility factor (b/a) & 0.35 & 5.2 \\
\hline
\end{tabular}



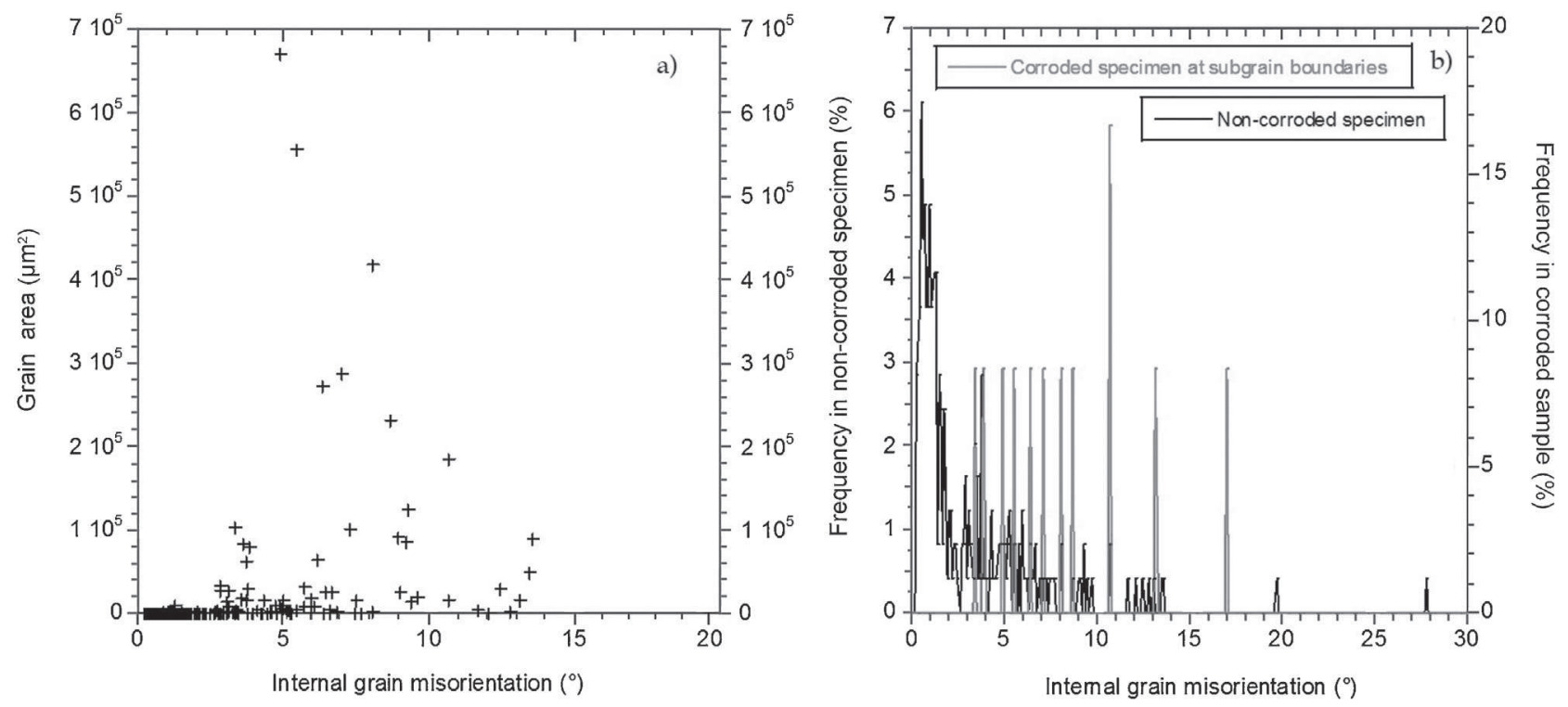

Fig. 8. AA 2050-T34 alloy-(a) Relationship between the grain surface area and the internal grain misorientation; (b) distribution of the internal grain misorientation before and after the corrosion tests for corrosion at the subgrain boundaries.

a certain type of interface (subgrain boundaries, random or CSL grain boundaries) divided by the proportion of interfaces of this same type in the sample. The results showed that the CSL grain boundaries were two times less sensitive to corrosion than the random grain boundaries, which was as expected from previous observations (Table 1). Moreover, the calculated indices showed that subgrain boundaries were the least sensitive interfaces. This result was partially consistent with the literature even if CSL grain boundaries were often considered more resistant than subgrain boundaries [20]. This trend must be further confirmed due to the low number of $\Sigma 3$ studied.

In light of the previous results, it was important to distinguish corrosion at grain boundaries and at subgrain boundaries for the AA 2050-T34 alloy. In both cases, the characteristics of the grains situated on each side of a corrosion defect (in the case of corrosion at the grain boundaries) or containing corrosion defects (in the case of corrosion at the subgrain boundaries) should influence the reactivity of the interface. Therefore, the properties of the grains were also investigated. The analyses performed prior to the corrosion tests showed that most of the grains were less than $10,000 \mu \mathrm{m}^{2}$ in area (Fig. 7a). More precisely, $50 \%$ of the grains measured less than $100 \mu \mathrm{m}^{2}$. After the corrosion tests, the grains containing corroded subgrain boundaries in the AA 2050-T34 samples were identified and their areas were recorded. Fig. 7a shows that the corrosion at subgrain boundaries occurred in grains with a large area $\left(>10,000 \mu \mathrm{m}^{2}\right.$, and more precisely $\left.>80,000 \mu \mathrm{m}^{2}\right)$. This was best explained by the presence of many subgrain boundaries and dislocations inside the large polygonized grains, leading to a significant amount of stored energy and consequently, a state of non-thermodynamic equilibrium in these grains. The analysis of corrosion at the grain boundaries of the AA 2050-T34 sample included examining the grains situated on both sides of the corrosion defects and recording their areas. Fig. 7a shows the distribution of the grains experiencing corrosion at their interfaces. Results highlighted that intergranular corrosion at grain boundaries occurred at the interface between grains of variable surface areas. But by drawing the distribution of the area ratio, which represents the area of the smallest grain divided by the area of the largest grain (for the grains situated on each side of a corrosion defect), a dominant group of corrosion defects for a low area ratio (0-0.2, Fig. $7 \mathrm{~b})$ was observed. This result means that in the AA 2050-T34 sample, intergranular corrosion developed mainly between grains with disparate areas: a galvanic coupling between a small grain and a large grain should explain this result because there is a stronger reactivity at their shared interface. Indeed, several works have shown that the corrosion potential of a metal varied with the dislocation density [24,25] and the grain size $[26,27]$. It was possible to transpose this result on the polycrystal scale by considering the galvanic coupling between grains of different sizes and possessing different dislocation densities.

The relationship between the grain size and dislocation density is shown in Fig. 8a for a non-corroded AA 2050-T34 sample where the dislocation density of a grain was measured through its internal misorientation. Fig. 8 a shows that the smallest grains have the smallest internal grain misorientation in relation to the low dislocation density. Moreover, the -T34 metallurgical state exhibited a high proportion of grains with a low internal misorientation $\left(<2^{\circ}\right.$, Fig. 8b). After the corrosion tests, the grains containing corroded subgrain boundaries for the AA 2050-T34 sample were identified and their internal misorientations recorded. As expected, corrosion at the subgrain boundaries occurred in grains containing a high internal misorientation (Fig. 8b). When considering the corrosion at the grain boundaries for the AA 2050-T34 sample, the ratio between the internal misorientation of each grain situated on each side of the corroded grain boundaries must be examined. The results showed that the corroded grain boundaries correlated to a high grain internal misorientation ratio, suggesting again that a galvanic coupling between the grains with different internal misorientations led to corrosion at their shared interface. Fig. 9 illustrates this phenomenon of galvanic coupling. Intergranular corrosion was observed at the interface between a grain with low internal misorientation (on the right of the corrosion defect $n^{\circ} 1$ ) and a grain with many subgrain boundaries, which assumed a high degree of internal misorientation (to the left of the corrosion defect marked $n^{\circ} 1$ ). It noted that despite of the average behaviour shown in Fig. 8a, the low internal misorientation within a grain is not necessarily associated with the small size of this grain (identified as the grain to the left of corrosion defect marked $n^{\circ} 2$ ). Therefore, to a greater extent than the grain size, the internal grain misorientation seems to be the most relevant parameter capable of explaining the intergranular corrosion susceptibility of the AA 2050-T34 alloy. 


\section{Corrosion defect $n^{\circ} 2$}
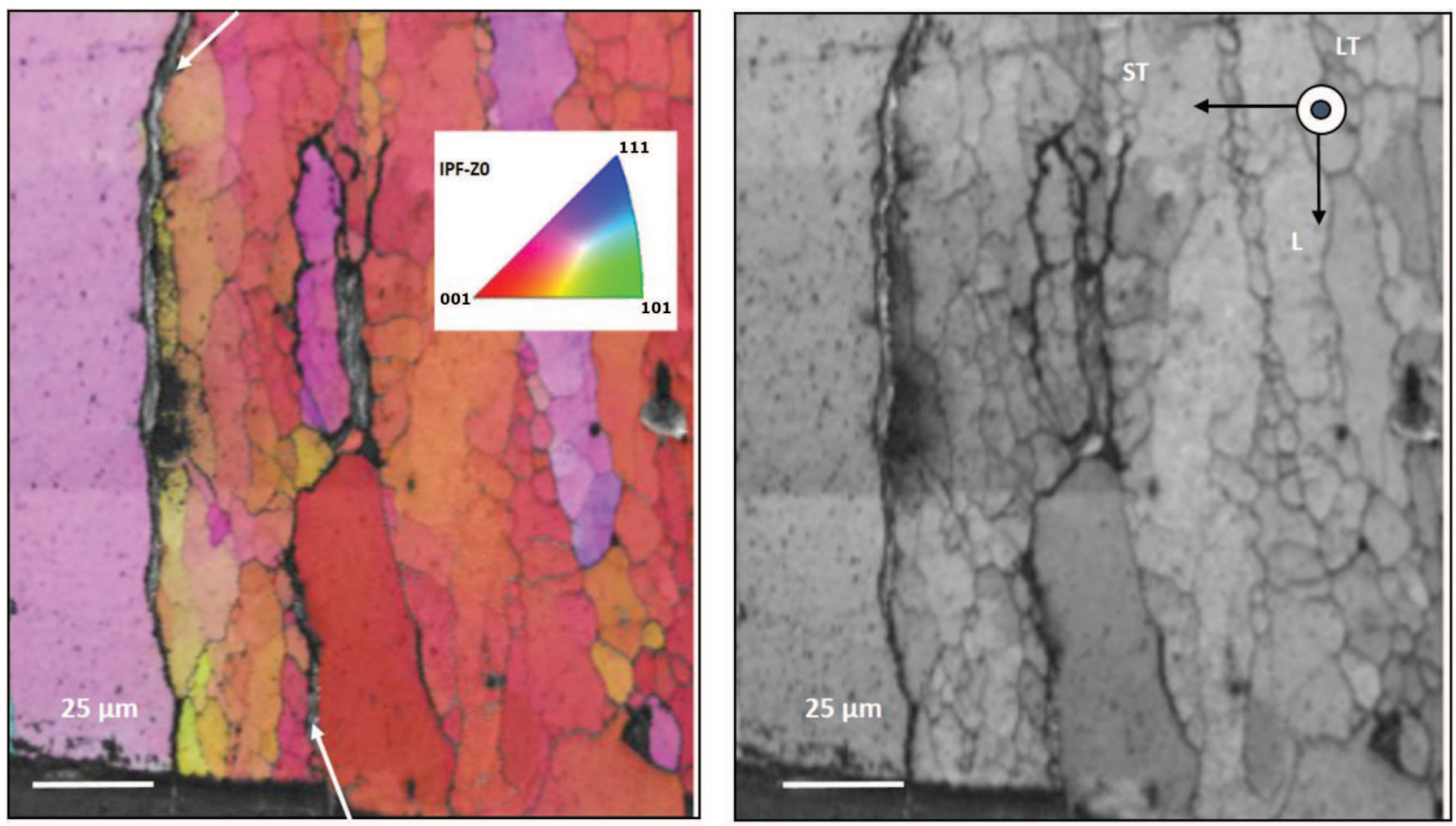

Corrosion defect $n^{\circ} 1$

Fig. 9. EBSD (IPF-Z0) micrograph of the corrosion defects situated between grains showing large discrepancies of internal misorientation in the AA 2050 -T34 alloy and the corresponding SEM micrograph.

\subsection{Corrosion behaviour of the AA 2050-T8 alloy}

The susceptibility to intragranular corrosion of AA 2050-T8 alloy was well-correlated to the homogeneous distribution of $\mathrm{T}_{1}$ precipitates both in the grains and at the grain boundaries. However, as previously noticed, such a structure of precipitation did not explain the preferential dissolution of some grains compared to the others. Results obtained for the AA 2050-T34 alloy suggested that metallurgical parameters at the polycrystal scale should contribute to explain the corrosion susceptibility of AA 2050-T8 alloy also. First, attention was paid to the influence of the grain size on the corrosion susceptibility. As for the AA 2050-T34 alloy, a strong reactivity of large grains was also observed for the AA 2050-T8 sample. The distribution of grains according to their area is presented in Fig. 10a for this metallurgical state. The distribution obtained for the AA 2050-T8 sample was similar to that of the AA 2050T34 sample because the ageing treatment did not modify the size of the grains. For the -T8 state, which is susceptible to intragranular corrosion, the analysis performed after the corrosion tests showed the preferential dissolution of grains with an area greater than $10,000 \mu \mathrm{m}^{2}$ (Fig. 10a). This result was in agreement with the data obtained for the AA 2050-T34 sample for corrosion at subgrain boundaries and was better explained by the presence of many subgrain boundaries and dislocations inside the large polygonized grains, leading to a significant amount of stored energy and consequently, a strong reactivity. The literature reports an evolution of the corrosion potential with the dislocation density but without any identified trends [25]. It was assumed in the present work that the grains with the highest dislocation density have the most negative corrosion potential. In contrast, the small recrystallised grains did not exhibit subgrain boundaries and their corrosion resistance was consequently higher.
Then, the influence of the internal misorientation of a grain on its corrosion susceptibility was considered. Concerning the relationship between the grain size and dislocation density, the same result was obtained for an AA 2050-T8 sample as for a non-corroded AA 2050-T34 sample (Fig. 8a), i.e. the smallest grains have the smallest internal grain misorientation. Moreover, as for the -T34, the non-corroded -T8 metallurgical states exhibited a high proportion of grains with a low internal misorientation $\left(<2^{\circ}\right.$, Fig. 10b). After the corrosion tests, results showed that intragranular corrosion occurred in grains containing a high internal misorientation (Fig. 10b) showing that the most relevant parameter capable of explaining the intragranular corrosion susceptibility of the AA 2050-T8 alloy was the internal misorientation of the grains, as for the intergranular corrosion susceptibility of the AA 2050-T34 alloy.

Another parameter was investigated in the AA 2050-T8 sample: the grain orientation related to the plane exposed to the electrolyte. The analysis performed after the corrosion tests on the -T8 state samples showed that the majority of the corroded grains are oriented according to (111) planes relative to the exposed plane (Fig. 11). It is worth noting that the (111) planes are the denser planes and they are the habit planes of the $T_{1}$ phase in the face centre cubic structure of aluminium. The literature reported that the dissolution behaviour of the grains depended on the orientation of the crystal relative to the plane exposed to the electrolyte [28]. Consequently, the preferential corrosion of grains oriented with the (111) planes exposed to the electrolyte may be explained by a more negative corrosion potential than for grains oriented to the other crystal planes. It is suggested that galvanic coupling between grains with different orientations led to the preferential corrosion of some grains. This hypothesis should be advanced to explain the susceptibility of the -T34 state to intergranular corrosion. In this case, galvanic coupling between grains with different orientations 

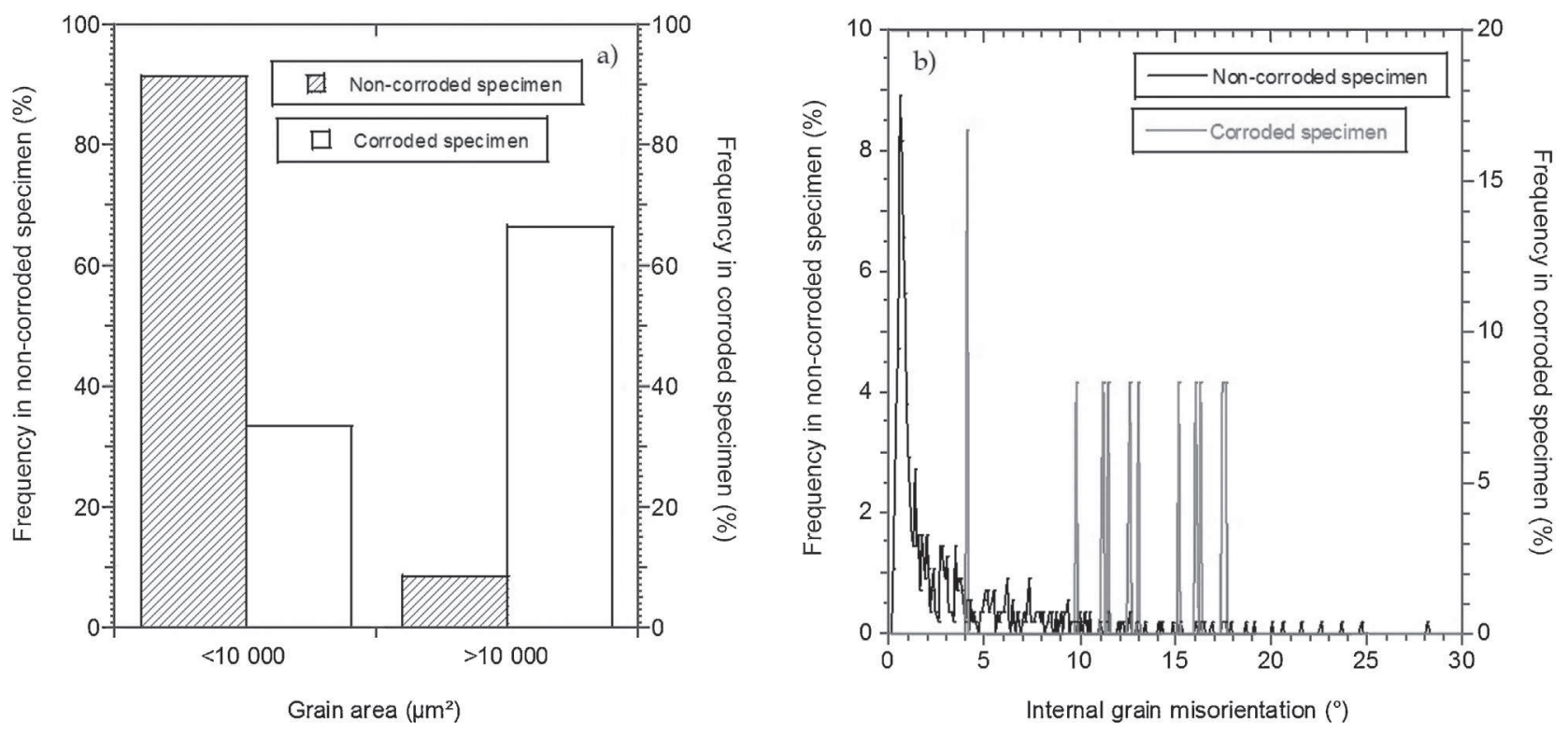

Fig. 10. AA 2050-T8 alloy-(a) Distribution of the grain surface areas and (b) distribution of the internal grain misorientation before and after the corrosion tests for intragranular corrosion.

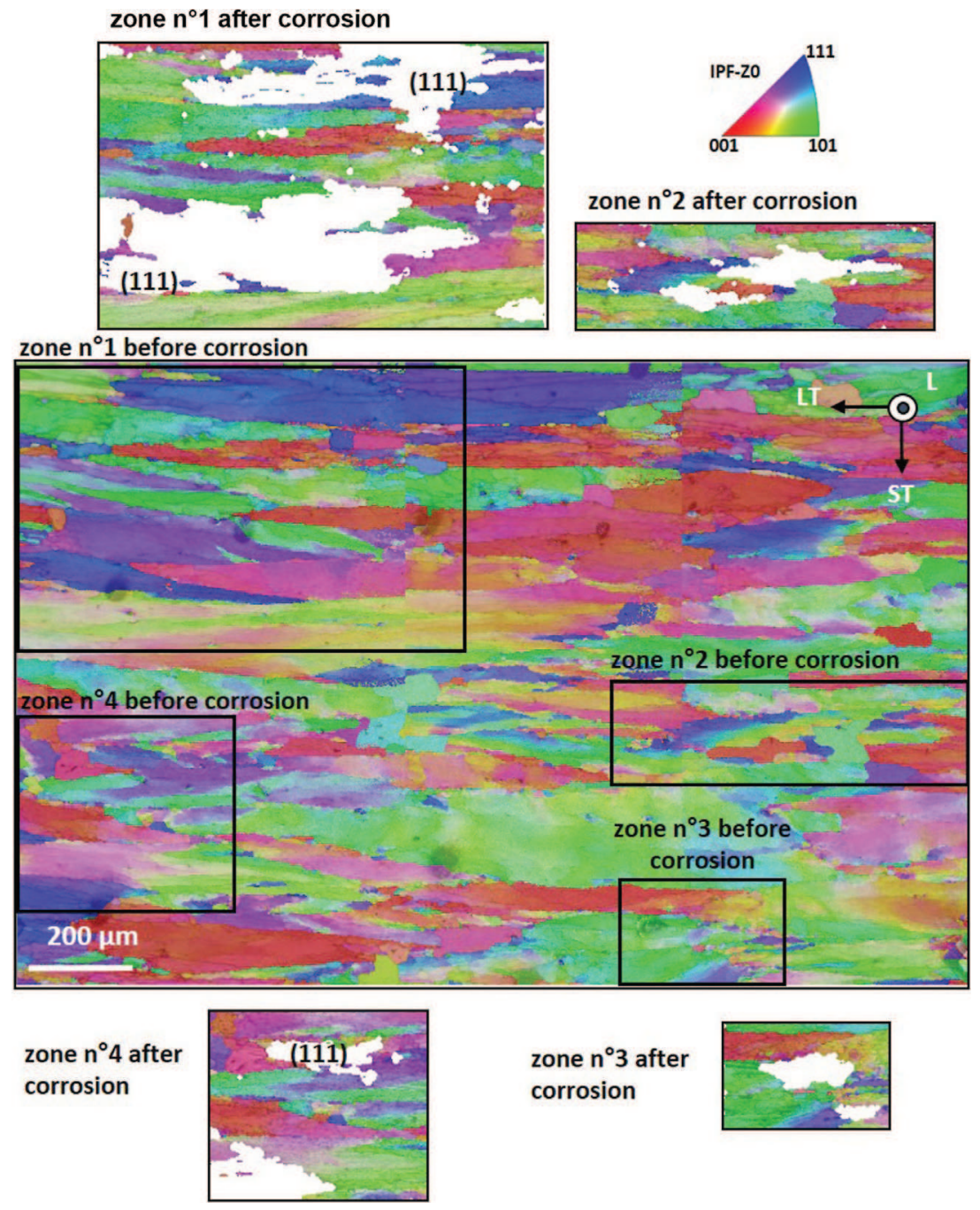

Fig. 11. EBSD (IPF-Z0) micrographs before and after corrosion tests in the AA 2050-T8 alloy. 
may increase the corrosion susceptibility of their shared interface. Further measurements of the Volta potential of the grains according to their crystalline orientation using Kelvin Force Microscopy should confirm this hypothesis.

\section{Conclusions}

The corrosion behaviour of AA 2050 was studied for both naturally aged (-T34) and artificially aged (-T8) metallurgical states. The impact of the microstructural parameters on both intergranular (-T34) and intragranular (-T8) corrosion mechanisms was investigated. The conclusions are as follows:

1 The structure of precipitation contributed to explain the susceptibility to corrosion of the AA 2050 alloy. However, the presence of $\mathrm{T}_{1}$ phase precipitates at the grain boundaries of a -T34 alloy was not necessary to sensitise the alloy to intergranular corrosion. The intragranular corrosion of a -T8 alloy can be explained partially by $\mathrm{T}_{1}$ precipitates homogeneously distributed in the grains and at the grain boundaries but such a homogeneous distribution did not explain the strong reactivity of some grains compared to others.

2 Other metallurgical parameters at the polycrystal scale were to be taken into account to explain the corrosion mechanisms in the AA 2050 alloy.

3 The nature of the interfaces was found to play a dominant role on the intergranular corrosion susceptibility of the -T34 alloy with a higher corrosion resistance for interfaces characterised by a low level of misorientation.

4 For both the -T34 and -T8 samples, the internal misorientation of the grains is a driving factor in the intergranular and intragranular corrosion mechanisms. Galvanic coupling between grains with strongly different internal misorientation should lead to the corrosion of their shared interface. Grains with high internal misorientation were found to be the most susceptible to corrosion.

5 For -T8 samples, grains oriented in the (111) planes, in which the $\mathrm{T}_{1}$ phase precipitated, were the most susceptible to intragranular corrosion.

\section{Acknowledgments}

This work was financially supported by the "PRES/Région MidiPyrénées". The authors would like to thank the Airbus Group for many fruitful discussions, Constellium for supplying the material. The TEM analyses were performed with the help of Marie-Christine Lafont.

\section{References}

[1] J.G. Rinker, M. Marek, Microstructure, toughness and stress corrosion cracking behavior of aluminum alloy 2020, Mater. Sci. Eng. 64 (1984) 203-221

[2] R.G. Buchheit, J.P. Moran, G.E. Stoner, Localized corrosion behavior of alloy 2090-the role of microstructure heterogeneity, Corrosion 46 (1990) 610-617

[3] P. Niskanen, T.H. Sanders, J.G. Rinker, M. Marek, Corrosion of aluminum alloys containing lithium, Corros. Sci. 22 (1982) 283-304.

[4] V. Proton, J. Alexis, E. Andrieu, J. Delfosse, A. Deschamps, F. De Geuser, M.C. Lafont, C. Blanc, The influence of artificial ageing on the corrosion behaviou of a 2050 aluminium-copper-lithium alloy, Corros. Sci. 80 (2014) 494-502.
[5] C. Kumai, J. Kusinski, G. Thomas, T.M. Devine, Influence of aging at $200^{\circ} \mathrm{C}$ on the corrosion resistance of Al-Li and Al-Li-Cu alloys, Corros. Sci. 45 (1989) 294-302.

[6] R.G. Buchheit, J.P. Moran, G.E. Stoner, Electrochemical behavior of $\mathrm{T}_{1}\left(\mathrm{Al}_{2} \mathrm{CuLi}\right)$ intermetallic compound and its role in localized corrosion of $\mathrm{Al}-2 \% \mathrm{Li}-3 \% \mathrm{Cu}$ alloys, Corrosion 50 (1994) 120-130.

[7] J.E. Kertz, P.I. Gouma, R.G. Buchheit, Localized corrosion susceptibility of $\mathrm{Al}-\mathrm{Li}-\mathrm{Cu}-\mathrm{Mg}-\mathrm{Zn}$ alloy $\mathrm{AF} / \mathrm{C} 458$ due to interrupted quenching from solutionizing temperatures, Metall. Mater. Trans. A 33 (2001) 2561-2573.

[8] H.Y. Li, Y. Tang, Z.D. Zeng, F. Zheng, Exfoliation corrosion of T6- and T3-aged AlxCuyLiz alloy, Trans. Non Ferrous Mater. Soc. China 18 (2008) 778-783.

[9] M. Guérin, E. Andrieu, G. Odemer, J. Alexis, C. Blanc, Effect of varying conditions of exposure to an aggressive medium on the corrosion behavior of the $2050 \mathrm{Al}-\mathrm{Cu}-\mathrm{Li}$ alloy, Corros. Sci. 85 (2014) 455-470.

[10] C. Luo, X. Zhou, G.E. Thompson, A.E. Hughes, Observations of intergranular corrosion in AA2024-T351: the influence of grain stored energy, Corros. Sci. 61 (2012) 35-44.

[11] S.H. Kim, U. Erb, K.T. Aust, G. Palumbo, Grain boundary character distribution and intergranular corrosion behaviour in high purity aluminium, Scr. Mater. 44 (2001) 835-839.

[12] J.G. Brunner, N. Birbilis, K.D. Ralston, S. Virtanen, Impact of ultrafine-grained microstructure on the corrosion of aluminium alloy AA2024, Corros. Sci. 57 (2012) 209-214.

[13] M. Winning, A.D. Rollett, Transition between low and high angle grain boundaries, Acta Mater. 53 (2005) 2901-2907.

[14] M. Tanaka, K. Higashida, K. Kaneko, S. Hata, M. Mitsuhara, Crack tip dislocations revealed by electron tomography in silicon single crystal, Scr. Mater. 59 (2008) 901-904.

[15] P. Donnadieu, Y. Shao, F. De Geuser, G.A. Botton, S. Lazar, M. Cheynet, M. De Boissieu, A. Deschamps, Atomic structure of $\mathrm{T}_{1}$ precipitates in $\mathrm{Al}-\mathrm{Li}-\mathrm{Cu}$ alloys revisited with HAADF-STEM imaging and small-angle X-ray scattering, Acta Mater. 59 (2011) 462-472.

[16] C. Dwyer, M. Weyland, L.Y. Chang, B.C. Muddle, Combined electron beam imaging and ab-initio modeling of $\mathrm{T}_{1}$ precipitates in $\mathrm{Al}-\mathrm{Li}-\mathrm{Cu}$ alloys, Appl. Phys. Lett. 98 (2011) 201909.

[17] Z. Gao, J.Z. Liu, J.H. Chen, S.Y. Duan, Z.R. Liu, W.Q. Ming, C.L. Wu, Formation mechanism of precipitate $\mathrm{T}_{1}$ in AlCuLi alloys, J. Alloy Compd. 624 (2015) 22-26.

[18] V. Araullo-Peters, B. Gault, F. de Geuser, A. Deschamps, J.M. Cairney, Microstructural evolution during ageing of $\mathrm{Al}-\mathrm{Cu}-\mathrm{Li}-\mathrm{X}$ alloys, Acta Mater. 66 (2014) 199-208.

[19] M. Froment, Sur le mécanisme de la corrosion intergranulaire des matériaux métalliques, J. Phys. Colloq. 36 (1975) 371-385.

[20] S.H. Kim, U. Erb, K. Aust, G. Palumbo, Grain boundary character distribution and intergranular corrosion behavior in high purity aluminum, Scr. Mater. 44 (2001) 835-839.

[21] V. Keast, D. Williams, Grain boundary chemistry, Curr. Opin. Solid State Mater. Sci. 5 (2001) 23-30.

[22] B.W. Bennett, H.W. Pickering, Effect of grain boundary structure on sensitization and corrosion of stainless steel, Metall. Trans. A 18 (1987) 1117-1124.

[23] S.R. Ortner, V. Randle, A study of the relation between grain boundary type and sensitisation in partially-sensitised AISI 304 stainless stell using electron back-scattering patterns, Scr. Metall. 23 (1989) 1903-1908.

[24] C. Luo, X. Zhou, G.E. Thompson, A.E. Hughes, Observations of intergranular corrosion in AA2024-T351: the influence of grain stored energy, Corros. Sci. 61 (2012) 35-44.

[25] S.R. Salimon, A.I. Salimon, A.M. Korsunsky, The evolution of electrochemical microstructural, and mechanical properties of aluminium alloy 2024-T4 (D16AT) during fatigue cycling, Proc. Inst. Mech. Eng. Part G (2010) 339-353.

[26] K.D. Ralston, D. Fabijanic, N. Birbilis, Effect of grain size on corrosion of high purity aluminium, Electrochim. Acta 56 (2011) 1729-1736.

[27] V. Proton, J. Alexis, E. Andrieu, J. Delfosse, M.-C. Lafont, C. Blanc, Characterisation and understanding of the corrosion behaviour of the nugget in a 2050 aluminium alloy friction stir welding joint, Corros. Sci. 73 (2013) $130-142$

[28] L. Lapeire, E. Martinez Lombardia, K. Verbeken, I. De Graeve, L.A.I. Kestens, H. Terryn, Effect of neighboring grains on the microscopic corrosion behavior of a grain in polycrystalline copper, Corros. Sci. 67 (2013) 179-183. 